ROCZNIKI FILOZOFICZNE

Tom LXVII, numer 3 - 2019

DOI: http://dx.doi.org/10.18290/rf.2019.67.3-6

\title{
ANDRZEJ WALESZCZYŃSKI
}

\section{MIĘDZY TROSKĄ A SPRAWIEDLIWOŚCIĄ - VIRGINII HELD POGLĄDY NA WSPÓLNOTĘ POLITYCZNĄ}

\section{WPROWADZENIE}

Dużo emocji towarzyszyło wprowadzeniu kategorii troski do współczesnych dyskusji z zakresu etyki i problematyki społeczno-politycznej. Jedną z najbardziej zagorzałych orędowniczek posługiwania się pojęciem troski w analizach moralnych jest Virginia Held ${ }^{1}$. Równocześnie jest ona jedną z prekursorek współczesnego kierunku w etyce, określanego jako etyka troski. Poglądy zwolenniczek i zwolenników tego nurtu od przeszło trzydziestu lat są szeroko komentowane, głównie w krajach kultury angloamerykańskiej. Szczególnie interesująca była wieloletnia debata poświęcona relacji między troską a sprawiedliwością, prowadzona z perspektywy filozoficznej. W polskiej literaturze brakuje publikacji poświęconych temu szczegółowemu zagadnieniu².

Celem niniejszego artykułu będzie zbadanie, co nowego do dyskusji o współczesnym społeczeństwie wnosi pojawienie się kategorii troski. Interesować nas będzie przede wszystkim relacja, jaka istnieje między kategorią troski a sprawiedliwości w debacie o kondycji współczesnej wspólnoty politycznej. Będziemy poszukiwali odpowiedzi na dwa zasadnicze pytania: Czy któraś z powyższych kategorii musi wieść prym w życiu politycznym? Czy

Dr ANDRZEJ WALESZCZYŃSKI — Uniwersytet Kardynała Stefana Wyszyńskiego, Wydział Filozofii Chrześcijańskiej, Instytut Filozofii; adres do korespondencji: ul. Wóycickiego 1/3, 01-938 Warszawa; e-mail: a.waleszczynski@uksw.edu.pl; ORCID: http://orcid.org/0000-0003-0426-3919.

${ }^{1}$ Virginia Held, The Ethics of Care: Personal, Political, and Global (New York: Oxford University Press, 2006).

${ }^{2}$ Do nielicznych można zaliczyć: Renata ZIEMIŃSKA, „Etyka troski i etyka sprawiedliwości. Czy moralność zależy od płci?," Analiza i Egzystencja 8 (2008): 115-32; Marta SoniewickA, Granice sprawiedliwości, sprawiedliwość ponad granicami (Warszawa: Wolters Kluwer Polska, 2010), 206-234. 
raczej są to kategorie, które na równi powinny wzajemnie egzystować obok siebie? A jeżeli tak, to czy jest to w ogóle możliwe do realizacji?

Skoncentrowanie się na poglądach jednej autorki podyktowane zostało obszerną i bogatą literaturą, a także dużą różnorodnością stanowisk w ramach etyki troski. Jak nie ma jednego feminizmu, tak również nie ma jednej koncepcji etyki troski i jednego spójnego stanowiska w sprawie relacji między troską a sprawiedliwością. Nasze analizy będą prowadzone przede wszystkim w odniesieniu do poglądów Virginii Held. Jest ona jedną z najważniejszych postaci tego nurtu i najbardziej zasłużoną propagatorką tej teorii moralności. To jej publikacje miały znaczący wpływ na kształt debaty o relacji między troską a sprawiedliwością ${ }^{3}$.

Poszukiwanie odpowiedzi na postawione pytania rozpoczniemy od przybliżenia kategorii troski we współczesnej filozofii, aby następnie skoncentrować się na jej rozumieniu, które w znacznej mierze zostało ukształtowane przez myśl feministyczną. Te wstępne badania pozwolą nam podjąć zagadnienie relacji troski jako fundamentu dla prawidłowego funkcjonowania wspólnoty społeczno-politycznej oraz krytyki idei kontraktu społecznego podejmowanego przez Held.

\section{KATEGORIA TROSKI WE WSPÓŁCZESNEJ FILOZOFII}

Współczesne zainteresowanie troską w ramach filozofii, a w szczególności etyki ${ }^{4}$, ma jedno zasadnicze źródło. Jest nim współczesna myśl feministyczna. Można, co prawda, wskazać publikacje, które pochodzą nawet z XIX wieku i podejmowały zagadnienie troski lub opieki, dla współczesnych jednak analiz i badań skoncentrowanych na problematyce troski stanowią one bardziej historyczną inspirację niż podstawowe dzieło dotyczące zagadnienia troski. W podobny sposób należy potraktować interpretacje poglądów Sokratesa w perspektywie troski o siebie i innych dokonywane przez Maurice'a Merleau-Ponty'ego, na które powołuje się Pierre Hadot ${ }^{5}$,

\footnotetext{
${ }^{3}$ Virginia Held, Feminist Morality: Transforming Culture, Society, and Politics (Chicago, London: The University of Chicago Press, 1993); EADEM, The Ethics of Care.

${ }^{4}$ Obecnie w języku polskim można wskazać trzy filozoficzne opracowania dotyczące etyki troski: Maciej UliŃSKI, Etyka troski i jej pogranicza (Kraków: Wydawnictwo Aureus, 2012); Aleksandra KAMIŃSKA, Spór wokót feministycznej etyki troski (Praca doktorska, Uniwerstytet Ślaski w Katowicach, 2008 - dostępna on-line: https://sbc.org.pl/Content/12050/doktorat2884.pdf); Andrzej WALESZCZYŃSKI, Feministyczna etyka troski. Zatożenia i Aspiracje (Warszawa: Środkowoeuropejski Instytut Zmiany Społecznej, 2013).

${ }^{5}$ Pierre НАDOт, Czym jest filozofia starożytna?, przeł. Piotr Domański (Warszawa: Fundacja Aletheia, 2000), 64-67.
} 
a także dokonywane w podobnym duchu odczytywanie historii filozofii przez Michela Foucault ${ }^{6}$. Tego typu zabiegi wskazują na pewne postawy filozoficzne lub sposoby uprawiania filozofii, a nie na uniwersalną kategorię troski, która mogłaby się stać podstawą etycznej oceny czynów.

Dlatego należy uznać, że na akademickie salony problematykę troski wprowadziła Carol Gilligan w 1982 r. książką In a Different Voice ${ }^{7}$. Do tego momentu, jak zauważa Warren T. Reich, pojęcie troski nigdy nie należało do głównych pojęć zachodnich koncepcji etyki ${ }^{8}$. Natomiast należały do nich pojęcia takie, jak wolność, sprawiedliwość czy miłość. Można jednak wskazać przypadki, w których pojęcie to odgrywało znaczącą rolę w zagadnieniach filozoficznych. Pojęcie troski pojawia się również w filozofii Martina Heideggera i może być kojarzone $\mathrm{z}$ jego egzystencjalizmem, w którym troska występuje jako jeden z opisów jestestwa ${ }^{9}$. Stosowana jednak przez niego kategoria nie odgrywa roli w jakimkolwiek nurcie w etyce. Filozofem, który najszerzej, z dotychczasowych myślicieli, zainteresował się pojęciem troski, jest Milton Mayeroff. W pracy wydanej w 1971 r., zatytułowanej po prostu On Caring, dostarczył szczegółowego opisu doświadczenia troski i podjął próbę jego wyjaśnienia. To on jako pierwszy, w swojej filozoficznej rozprawie, ukazał troskę jako dynamiczną relację, która nadaje sens ludzkiemu życiu ${ }^{10}$.

Interesujące jest to, że dopiero pod koniec XX wieku troska pojawia się jako oddzielna kategoria etyczna. W tradycyjnej zachodniej etyce podstawowymi kategoriami były różnie rozumiane dobro (jako cel ludzkiego postępowania) i prawo (Boże, naturalne, prawa człowieka), a także cnota stojąca trochę obok tych kategorii. Dlatego pojawienie się troski jako kategorii etycznej wywoływało, z jednej strony, zainteresowanie, z drugiej zaś narażało ją na duży sceptycyzm. Troska, jako nowa kategoria etyczna, została zbudowana w opozycji do kategorii sprawiedliwości. Do polaryzacji podziału „troska versus sprawiedliwość” przyczyniły się badania Lawrenca

\footnotetext{
${ }^{6}$ Michel Foucault, Historia seksualności, przeł. Bogdan Banasiak, Tadeusz Komendant i in. (Warszawa: Czytelnik, 2000), 381-597.

${ }^{7}$ Carol Gilligan, In a Different Voice: Psychological Theory and Women's Development (Cambridge: Harvard University Press, 1982).

${ }^{8}$ Warren T. ReICHT, „History of the Notion of Care”, w: Encyclopedia of Bioethics, red. Warren T. Reicht, $2^{\text {nd }}$ ed. (New York: Macmillan Library Reference, 1995), 319-320.

${ }^{9}$ Martin Heidegger, Bycie i czas, przeł. Bogdan Baran (Warszawa: Wydawnictwo Naukowe PWN, 1994), 256-283, 354-375.

${ }^{10}$ Milton Mayeroff, On Caring (New York: Harper \& Row, 1971), 40-42.
} 
Kohlberga nad rozwojem moralnym ${ }^{11}$. To on zaproponował etapy rozwoju moralnego, których zwieńczeniem jest postępowanie człowieka oparte na zasadach sprawiedliwości inspirowanych etyką Immanuela Kanta i Johna Rawlsa. Empirycznym problemem okazał się fakt, że w przeprowadzanych badaniach kobiety bardzo rzadko osiagały najwyższy poziom rozwoju moralnego. Skłoniło to jego uczennicę, wspomnianą już Carol Gilligan, do przeprowadzenia własnych badań. Wykazały one, że kobiety w swoim postępowaniu kierują się przede wszystkim troską, a nie sprawiedliwością. Zauważyła, że kobiety, podejmując decyzje moralne, nie koncentrują się na zasadach opartych na sprawiedliwości, ale na tym, jak konkretne decyzje moga wpłynać na relacje z poszczególnymi osobami. Dlatego w rozumieniu Gilligan troska jawi się jako troska o relacje z konkretnymi innymi. Dostrzeżony przez Gilligan tytułowy „inny głos” kobiet, który został opisany w jej książce, stworzył podwaliny dla pojawienia się współczesnego zainteresowania kategorią troski.

Pierwszą jednak filozoficzną pracą skoncentrowaną na trosce i wypływająca z feministycznych źródeł była publikacja Nel Noddings ${ }^{12}$ z 1984 r. z zakresu filozofii edukacji. To właśnie ona wywarła największy wpływ na dalsze filozoficzne i zarazem feministyczne analizy dotyczące troski jako kategorii etycznej. Noddings w swojej pracy skoncentrowała się na relacji między wychowankiem a wychowawcą. Wskazała ona normatywne wymagania dla osób troszczących się i potrzebujących troski. Według Noddings troska ujawnia się w konkretnych działaniach i to właśnie one o wiele bardziej niż abstrakcyjne intencje definiują rzeczywistą troskę ${ }^{13}$. Jej interpretacja troski wywarła olbrzymi wpływ na sposób rozumienia troski w ramach całego nurtu etyki troski.

\section{ETYKI TROSKI I FEMINIZM}

Pojawienie się, za sprawą Gilligan i Noddings, na filozoficznym areopagu kategorii troski jako konkurentki sprawiedliwości wymagało od uczestników dyskusji z zakresu filozofii odpowiedzenia na dodatkowe pytania i dokona-

\footnotetext{
${ }^{11}$ Lawrence KoHLBERG, „From is to ought: How to commit the naturalistic fallacy and get away with it in the study of moral development", in Cognitive development and epistemology, red. Theodore Mischel (New York: Academic Press, 1971), 151-235.

${ }^{12}$ Nel NodDings, Caring: A Feminine Approach to Ethics and Moral Education (Berkeley: University of California Press, 1984), 21-24.

${ }^{13}$ Ibid.
} 
nia rozstrzygnięć, dotyczących nowych pojawiających się trudności. Dostrzeżenie „innego głosu”, którym przemawiają kobiety, z jednej strony pozwoliło z nowej perspektywy spojrzeć na sprawy kobiet, a w szczególności na zagadnienia moralne, $\mathrm{z}$ drugiej strony sugerowało istnienie jednego kobiecego głosu. Ta druga perspektywa wywołała wewnętrzną krytykę w gronie samych feministek. „Inny głos” kobiet zaczął być postrzegany jako głos białej protestanckiej kobiety z klasy średniej, żyjącej w Stanach Zjednoczonych. Szybko do głosu doszły różnice rasowe i etniczne, tak bardzo widoczne w Ameryce Północnej. Dlatego wśród feministek nasiliła się krytyka wizji jednego zunifikowanego głosu, który miałby reprezentować wszystkie kobiety. Swoją odrębność mocno zamanifestowały zwolenniczki odrębnego głosu dla „kobiet kolorowych”, do których można zaliczyć Susan J. Hekman $^{14}$, Suzanne Carothers ${ }^{15}$, Ritę Manning ${ }^{16}$ czy Carol Stack ${ }^{17}$.

Krytycznemu spojrzeniu na rodzącą się etykę troski wewnątrz samego feminizmu towarzyszyła debata bardziej ogólnofilozoficzna. Jeden z jej wciąż aktualnych problemów dotyczył przenoszenia wniosków wyciąganych na podstawie badań psychologicznych na założenia filozoficzne. Określenie procesu rozwoju moralnego człowieka i zróżnicowanie go ze względu na płeć jest jedną sprawą, natomiast drugą jest bezpośrednie przenoszenie wniosków wysuwanych w obszarze psychologii na zagadnienia filozoficzne. Gilligan nie dostrzega tego, że sama popełnia błąd, który krytykuje u Kohlberga. Różnica polega na tym, że przesuwa ona środek ciężkości z męskiego na kobiece spojrzenie na rozstrzyganie problemów moralnych. Czym innym jest dostrzeganie kulturowych, psychologicznych czy socjologicznych różnic wynikających z doświadczenia obu płci, a czym innym konstruowanie na tej podstawie założeń lub koncepcji filozoficznych. Podział na sferę publiczną zdominowaną przez mężczyzn i prywatną, w której dominują kobiety, może, na co zwraca uwagę Jean Grimshaw, stanowić podstawę tworzenia się odmiennych priorytetów etycznych przypisywanych poszczególnym płciom. Nie oznacza to jednak, że doświadczenie kobiet, np. przeżywania macierzyństwa,

\footnotetext{
${ }^{14}$ Susan J. Hekman, Moral Voices, Moral Selves: Carol Giligan and Feminist Moral Theory (Pennsylvania: Pennsylvania State University Press, 1995): 108.

${ }^{15}$ Suzanne CARothers, „Catching Sense: Learning from Our Mothers to Be Black and Female," w: Uncertain Terms, red. Faye Ginsburg and Anna Tsing (Boston: Beacon Press, 1990): 232-247.

${ }^{16}$ Rita MANNING, Speaking from the Heart: A Feminist Perspective on Ethics (Lanham: Rowman \& Littlefield Publishers, 1992).

${ }^{17}$ Carol STACK, „Different Voices, Different Visions: Gender, Culture, and Moral Reasoning”, w: Uncertain Terms, red. Faye Ginsburg i Anna Tsing (Boston: Beacon Press, 1990): 19-27.
} 
doświadczenia opresji, nie może stanowić źródła krytyki zdominowanej przez mężczyzn sfery publicznej lub koncepcji etycznych takich jak teoria sprawiedliwości Rawlsa, koncentrujących się wyłącznie na etyce życia społecznego ${ }^{18}$.

Gilligan swoimi badaniami z zakresu psychologii dowartościowała kobiece spojrzenie na moralność, ale tym samym wprowadziła do dyskusji etycznej dualizm czy wręcz opozycję: sprawiedliwość vs. troska. Problem ten został dostrzeżony m.in. przez Owena Flanagana i Kathryn Jackson, którzy wskazali na późniejsze wobec Gilligan badania, ukazujące fakt, że większość ludzi, bez względu na płeć, przy ocenach moralnych wykorzystuje obie perspektywy, tzn. troski i sprawiedliwości ${ }^{19}$. W jednym przypadku ludzie wskazują na czynniki normatywne, wykorzystując perspektywę sprawiedliwości, natomiast w innym odwołują się do uwarunkowań wynikających z konkretnych sytuacji i przyjmują perspektywę troski. Oznacza to, że większość nie przyjmuje wyłącznie jednej perspektywy rozstrzygania problemów moralnych.

Innym problemem $\mathrm{z}$ perspektywy filozoficznej jest to, czy uzasadniony jest dychotomiczny podział ludzkości ze względu na płeć w obszarze etyki. Dostrzeżona przez Gilligan różnica w rozwiązywaniu problemów moralnych jest podbudowana pewnym szerszym kontekstem myśli feministycznej. W nim to funkcjonuje pewna opozycja między tym, co męskie, a tym, co kobiece. Świat mężczyzn jest reprezentowany przez racjonalność, abstrakcyjne zasady, bezstronność i neutralność, a także indywidualną autonomię. W opozycji do tak przedstawianej rzeczywistości świat kobiet jest reprezentowany przez emocjonalność, stronniczość i partykularność, skupianie się na konkretnych relacjach i przypadkach, a także na współzależności od innych. Tę szerszą dychotomię wzmocniły wyniki badań Gilligan i przeniosły ją na grunt etyki, tworząc opozycję: etyka troski vs. etyka sprawiedliwości. Zaistniały podział należy jednak rozpatrywać w szerszym kontekście filozoficznym.

Etapy rozwoju moralnego człowieka, wskazane i scharakteryzowane przez Kolhberga, były porządkowane w odniesieniu do etyki opartej na teorii sprawiedliwości, głównie w wersji zaproponowanej przez Johna Rawlsa. Natomiast sam Rawls jest spadkobiercą Immanuela Kanta i jego założeń filozoficznych. Innymi słowy, konfrontując zagadnienie troski z zagadnieniem sprawiedliwości, należy mieć na uwadze, że odnosi się ono do etyki życia

\footnotetext{
${ }^{18}$ Jean GrimSHaw, „Czy istnieje etyka kobieca?”, w: Przewodnik po etyce, red. Peter Singer, przeł. Robert Pucek, Paweł Łuków i in. (Warszawa: Wydawnictwo KsIĄżKA I WIEDZA, 2009): 544-545.

${ }^{19}$ Owen Flanagan i Kathryn JACKSON, „Justice, Care, and Gender: The Kohlberg-Gilligan Debate Revisited”, Ethics 97 (1987), no. 3 (April): 623-631.
} 
publicznego i tylko do wycinka dziedzictwa etyki, o czym osoby analizujące tę problematykę niejednokrotnie zapominają. Widać to bardzo dobrze m.in. $\mathrm{w}$ pracy Joan Tronto $^{20}$, która zestawiając etykę sprawiedliwości $\mathrm{z}$ etyką troski, wskazuje na różnice występujące $\mathrm{w}$ trzech kategoriach ${ }^{21}$ : dyspozycji, rozumowania i pojęć moralnych. Etykę troski ma charakteryzować rozwijanie dyspozycji moralnych, poszukiwanie rozwiązań właściwych w konkretnym przypadku, koncentracja na obowiązkach i relacjach. Wymienione cechy mają stać w opozycji do całego męskiego świata, opartego na uniwersalnych zasadach moralnych, kładących nacisk na prawa i bezstronność. Na gruncie filozofii amerykańskiej szeroko rozumianych lat 80 . taki zabieg wydaje się zrozumiały, ale nieuzasadniony. Retorycznie można zapytać, jak na tym tle przedstawia się etyka cnót, która kładzie nacisk właśnie na rozwój sprawności moralnych, a obecnie $w$ ramach etyki troski jest rozwijana przez Michela Slote'a. Co z wkładem do dorobku etycznego filozofii dialogu, a w szczególności Emmanuela Levinasa, który na pierwszym miejscu stawia właśnie relację Ja-Ty, a nie na abstrakcyjne zasady? Co z dorobkiem etyki odpowiedzialności, a w jej ramach Hansa Jonasa, który posługuje się zasadami, ale u ich podstaw jako wzór stawia relację między matką a dzieckiem i wynikające z niej zobowiązania? Pominięcie, w kontekście dyskusji o relacji między troską a sprawiedliwością, dorobku materialnej etyki wartości, a w jej ramach wkładu samego Maxa Schelera, również zaprzecza przedstawianym przez feministki dychotomiom: troska-sprawiedliwość, racjonalność-emocjonalność, zasady-relacje. Posługiwanie się pojęciem wartości, a nie zasad oraz emocjonalnym, a nie racjonalnym odkrywaniem samych wartości lokuje „męską” etykę wartości Schelera po stronie „kobiecej” etyki troski. Również tradycja chrześcijańskiego personalizmu w znacznej mierze stoi w opozycji do założeń etycznych teorii sprawiedliwości Johna Rawlsa i preskryptywizmu Richarda M. Hare'a, który również wywarł istotny wpływ na poglądy Kohlberga.

Ukazany powyżej szerszy kontekst filozoficzny pokazuje, że radykalizm, z jakim była i czasami jeszcze jest przedstawiana opozycja etyka troskietyka sprawiedliwości, dotyczy istotnego, ale tylko wycinka tradycji etycznej. Dopiero dyskusje z przełomu lat 80 . i 90 . pokazały potrzebę komplementarności obu typów stanowisk ${ }^{22}$ i wypracowania takiej wersji etyki

\footnotetext{
${ }^{20}$ Joan C. Tronto, „Beyond Gender Difference to a Theory of Care”, Signs: Journal of Women in Culture and Society 12 (1987), no. 4 (July): 644-663.

${ }^{21}$ Will KymlickA, Wspótczesna Filozofia Polityczna (Kraków: Wydawnictwo ZNAK, 1998): 290-301.

${ }^{22}$ Między innymi: Annette C. BAIER, Moral Prejudices: Essays on Ethics (Cambridge: Harvard University Press, 1994); Marilyn FrIEDMAn, What Are Friends For?: Feminist Perspectives
} 
troski, która będzie sobie radziła $\mathrm{z}$ zagadnieniem sprawiedliwości $\mathrm{w}$ życiu prywatnym i publicznym. Należy nadmienić, że powyższe uwagi dotyczące opozycji troska-sprawiedliwość, nie tyle deprecjonują etykę troski, co raczej pokazują, że etyka troski w nowy sposób podejmuje zagadnienia bardzo istotne w etyce, które niejednokrotnie były odsunięte na boczny tor rozważań filozoficznych lub wręcz zapominane. Równocześnie należy przyznać, że feministyczny wkład w rozwój myśli etycznej i rozwiązań proponowanych przez poszczególne myślicielki na trwałe wpisał się w historię etyki. Nie chodzi tu wyłącznie o koncentrację na relacjach, na które szczególną uwagę zwracają przedstawicielki etyki troski, ale również na takie propozycje jak stanowisko Luce Irigaray $\mathrm{z}$ jej etyką różnicy płciowej ${ }^{23}$, która wskazuje na ontologiczną różnicę między mężczyznami a kobietami. Dlatego, odnosząc się do zagadnienia troski i problematyki moralnej, należy zadać pytania: Czy posługiwanie się kategorią troski nie prowadzi do subiektywizmu lub relatywizmu etycznego? Czy kobiece moralne doświadczenie troski jest specyficznie kobiece? Jak wyglądałaby etyka społeczna zbudowana na troskliwych relacjach? Chcąc odpowiedzieć na te istotne pytania, w pierwszej kolejności musimy uzmysłowić sobie, jak jest rozumiana troska, bo bez jej zdefiniowania uzyskane odpowiedzi mogą być przeciwstawne.

\section{ROZUMIENIE TROSKI}

Chcąc właściwie odczytać znaczenie kategorii troski dla współczesnej etyki i teorii polityki oraz jej konfliktu z kategorią sprawiedliwości, należy odpowiedzieć sobie, czym jest troska. Bez wątpienia poglądy Noddings miały istotny wpływ na rozumienie troski ${ }^{24}$ przez feministyczne teoretyczki, to jednak Held więcej uwagi poświęcała relacjom społeczno-politycznym. Noddings w rozwijanej przez siebie koncepcji moralności koncentruje się na wartości ustanawiania i utrzymywania troskliwych relacji. To właśnie troskliwe

on Personal Relationships and Moral Theory (Ithaca: Cornell University Press, 1993); Joan C. Tronto, Moral Boundaries. A Political Argument for an Ethic of Care (New York, London: Routledge, 1993); Susan Moller OKIN, „Reason and Feeling in Thinking about Justice”, Ethics 99 (1989), No. 2 (Jan.): 229-249; Virginia Held, Rights and Goods. Justifying Social Action (Chicago: University of Chicago Press, 1989).

${ }^{23}$ Luce IrIgaray, Sexes and Genealogies (New York: Columbia University Press, 1993); EADEM, I Love to You: Sketch for a Felicity within History (New York, London: Routledge, 1996).

${ }^{24}$ Bardziej szczegółowe omówienie rozumienia pojęcia troski we współczesnej etyce feministycznej można znaleźć w: Andrzej WALESZCZYŃSKI, „Pojęcie troski we współczesnej etyce”, Studia Philosophiae Christianae 48 (2012), nr 2: 143-157. 
relacje są postrzegane jako dobre ze swej istoty ${ }^{25}$. Wynikiem doświadczania przez ludzi troskliwych relacji w okresie niemowlęcym jest postrzeganie tych relacji jako dobrych samych z siebie. W swoich poglądach Noddings idzie nawet dalej. Uważa, że bez doświadczenia troski w czasie, gdy byliśmy zależni od rodziców, nie moglibyśmy być istotami moralnymi, a relacje troski należy uznać za moralnie podstawowe ${ }^{26}$.

Held w swojej wizji troski wzmacnia stanowisko, jakie zajęła Noddings. Dla Held troska również jest relacją. Wyjątkowość tej relacji w jej ujęciu polega na tym, że napotykamy w niej potrzeby konkretnych osób, za które bierzemy odpowiedzialnośćc ${ }^{27}$. Troska jest relacją, w której troszczący się i doznający troski wspólnie uczestniczą $\mathrm{w}$ ich wzajemnej pomyślności ${ }^{28}$. W podobny sposób troskę będą postrzegały Demiut Bubeck ${ }^{29}$, a ostatnio także Sara Clark Miller ${ }^{30}$. Istniejąca relacja powinna mieć również charakter więzi emocjonalnej, powstałej między osobami stanowiącymi jej krańce. Osoby powinny dążyć do rozwoju relacji w takim kierunku, aby motywem działania były także uczucia. Pewnym mankamentem pozostaje to, że nie wskazuje ona, jak to uczynić. Emocje i uczucia mają stanowić motywy dla rozwoju troskliwej relacji, w czego konsekwencji relacja stanie się lepsza ${ }^{31}$.

Trzeba dodać, że Held przejmuje od Bubeck definicję potrzeby. „Potrzeba ma taką naturę, że nie może zostać spotkana przez osobę, która sama jest w potrzebie"32. Oznacza to, że nie każda potrzeba ma wymiar moralny. Chcąc to doprecyzować, Held odwołuje się do poglądów Sary Ruddick, dla której człowiek domaga się, tak jak dziecko od matki, trzech rzeczy. Po pierwsze, ochrony i zachowania jego życia; po drugie, wspierania jego rozwoju; po trzecie, tego, żeby jego rozwój był kształtowany w sposób akceptowany przez następne pokolenie ${ }^{33}$. W kontekście społecznym szczególnie istotna będzie pierwsza $\mathrm{z}$ wymienionych potrzeb. Brak odpowiedzi na tę podsta-

\footnotetext{
${ }^{25}$ NodDings, Caring, 83.

${ }^{26}$ Nel NodDings, The Maternal Factor: Two Paths to Morality (Berkeley: University of California Press, 2010): 33.

${ }^{27}$ HELD, The Ethics of Care, 10.

${ }^{28}$ Ibid., 34-35.

${ }^{29}$ Diemut BuBEck, Care, Gender and Justice (Oxford: Oxford University Press, 1995).

${ }^{30}$ Sarah Clark Miller, The Ethics of Need. Agency, Dignity, and Obligation (New York: Routledge, 2012).

${ }^{31}$ Virginia HeLD, „Moral Subjects: The Natural and the Normative”, Proceedings and Addresses of the American Philosophical Association 76 (2002), No. 2 (November): 7-24.

${ }^{32}$ BuBECK, Care, Gender and Justice: 129.

${ }^{33}$ Sara RuDDICK, ,Maternal Thinking”, w: Feminist Social Thought. A Reader, red. Diana T. Meyers (New York, London: Routledge, 1997), 589.
} 
wową potrzebę prowadzi do tego, że niemożliwe byłoby zachowanie przy życiu nie tylko konkretnego człowieka, ale i całego społeczeństwa. Odpowiadanie na potrzeby ma pomagać $w$ budowaniu zaufania i lepszego społeczeństwa, co równocześnie stanowi cel etyki w rozumieniu Held ${ }^{34}$.

Stanowisko zajmowane przez Noddings i Held w rozumieniu troski, które można uznać za klasyczne, jest niekiedy określane jako monizm wartości ${ }^{35}$, gdyż wskazania moralne są podporządkowane jednej centralnej wartości, jaką jest troska. Takie ujęcie jest przeciwstawiane stanowisku pluralistycznemu, w którym jest miejsce również na inne wartości, takie jak autonomia jednostki, dobre życie, czy sprawiedliwość. Joseph Walsh chociaż zgadza się, że etyka oparta na trosce jest zazwyczaj przedstawiana jako forma monizmu wartości, to jednak twierdzi, że jest bardziej zrozumiała jako forma pluralizmu wartości ${ }^{36}$. Pogląd taki należy uznać za błędny $\mathrm{z}$ co najmniej dwóch powodów. Po pierwsze, zaklasyfikowanie etyki troski jako formy teorii aksjologicznej stanowi istotny błąd. Etyka troski w klasycznym jej rozumieniu jest etyką relacyjną. To właśnie stanowi jej główny wkład w rozwój współczesnej etyki. Koncentracja na troskliwych relacjach jako źródle zobowiązania moralnego stanowi istotny jej wyróżnik. Po drugie, postawienie troski $\mathrm{w}$ jednym szeregu $\mathrm{z}$ innymi wartościami, a w szczególności ze sprawiedliwością, wskazuje nie tylko na brak zrozumienia całego projektu feministycznej etyki, ale także podstawowych założeń, które stoją u jej podstaw. Dlatego w kolejnych punktach zajmiemy się tym, jak w perspektywie relacji troski Held rozumie stosunki społeczno-polityczne z kluczową dla liberalnych wspólnot politycznych kategorią sprawiedliwości.

\section{RELACJA TROSKI \\ JAKO PODSTAWA WIĘZI SPOŁECZNEJ}

Troska rozumiana jako relacja istnieje między troszczącą się osobą a osobą potrzebującą troski. Tak rozumiana troska stanowi najbardziej podstawową wartość moralną, a dokładniej — pewien idealny wzór dla ludzkiego postępowania. Ten idealny wzór tworzony jest poprzez troskliwe praktyki, bez których życie człowieka nie jest w ogóle możliwe, ponieważ ludzie nie

\footnotetext{
${ }^{34}$ Virginia HeLD, Rights and Goods. Justifying Social Action (Chicago: University of Chicago Press, 1989), 65-69, 82-85.

${ }^{35}$ Joseph P. WALSH, „Caring: A Pluralist Account”, Ratio 31, No. S1 (2018): 96-110.

${ }^{36}$ Ibid., 109.
} 
mogliby bez niej przetrwać. To dzięki trosce jako praktyce możliwe jest pojawienie się w danym społeczeństwie troski jako wartości, czyli idealnego wzorca troskliwego postępowania. Dlatego też bez zapewnienia pewnego poziomu troskliwej obawy o życie innych ludzi nie byłoby w ogóle moralności. Proces moralnego oceniania ludzkiej działalności jest, jak podkreśla Held, potrzebny w wielu kontekstach troski ${ }^{37}$.

Chcąc dostrzec znaczenie kategorii troski dla zrozumienia relacji społecznych, należy przyjrzeć się jej dokładnie. Held posługuje się terminem „troskliwa osoba” (caring person), który wyparł w jej publikacjach termin „matczyna osoba” (mothering person) ${ }^{38}$. To drugie jednak określenie wyraźniej ukazuje rozumienie relacji troski. Held posługiwała się terminem „matczyna osoba” w celu odejścia od terminu „matka”, ale także innych terminów (również neutralnych rodzajowo w języku angielskim), takich jak „opiekun”, „pielęgniarz”, „rodzic”. Posługiwanie się terminem „matczyna osoba" ma być kompromisem co do rodzaju. Zdaniem Diany T. Meyers jest to jednak dziwny neologizm ${ }^{39}$. Trzeba jednak pamiętać, że mówiąc o troskliwej lub matczynej osobie, Held wskazuje nie tyle na samą osobę i posiadaną przez nią cnotę troski, ile na troskliwe relacje, w których ona uczestniczy.

Odwołując się do istniejącej praktyki troski, należy mieć na uwadze, że troska jest także wartością. Troszcząca się osoba i motywy relacji troski powinny być wartościowane i oceniane. Troska nie jest tym samym co dobroduszność lub życzliwość, ponieważ jest ona społeczną relacją, która nie da się zredukować do indywidualnych stanów. Wartość troszczenia się przejawia się przede wszystkim $\mathrm{w}$ relacjach troski, a nie $\mathrm{w}$ osobach jako indywiduach $^{40}$. W etyce troski centralna jest relacja troski, a nie troskliwa osoba, która odznacza się cnotą troski, choć troskliwe osoby są w relacji troski niezbędne ${ }^{41}$. Rozumienie troski jako relacji nieredukowalnej do cech indywidualnych jest bardzo istotne, ponieważ wśród przedstawicieli etyki cnót, takich jak Michael Slote ${ }^{42}$, istnieje tendencja do ograniczania troski właśnie do cnoty i odrzucenia jej rozumienia jako relacji.

\footnotetext{
${ }^{37}$ Held, The Ethics of Care: Personal, Political, and Global: 73.

${ }^{38}$ Held, Feminist Morality, 213; EAdEM, The Ethics of Care, 77.

${ }^{39}$ Diana T. MEYERS, ,Tropes of Social Relations and the Problem of Tropisms in Figurative Discourse," w: Norms and Values: Essays on the Work of Virginia Held, red. Joram Graf Haber i Mark S. Halfon (Lanham, Boulder, New York, Oxfrod: Rowman \& Littlefield Publishers, 1998): 52.

${ }^{40}$ HeLD, The Ethics of Care, 42.

${ }^{41}$ Ibid., 96.

${ }^{42}$ Michael SLOTE, Morals from Motives (New York: Oxford University Press, 2001), 77.
} 
Dlaczego „prawzorem” troskliwej relacji, a także relacji społecznych, stała się relacja matka-dziecko? Held często podkreśla, że każda osoba zaczyna swoje istnienie jako dziecko całkowicie zależne od okazywanej mu troski. Dziecko od momentu narodzin ma potrzeby, na które samo nie jest W stanie odpowiedzieć. W związku z tym człowiek jest przez nią postrzegany jako osoba relacyjna i współzależna (interdependent), a nie samostanowiące się niezależne indywiduum. Weźmy pod uwagę fakt, że większość relacji można, jak słusznie wskazuje Held, określić jako niedobrowolne i współzależne. Wtedy zasadne wydaje się zastosowane określenia „matczyna osoba”, gdyż na przykładzie relacji matka-dziecko wyraźnie widać niedobrowolność i współzależność wynikającą $\mathrm{z}$ tego typu relacji. Napotykamy je nie tylko w okresie dzieciństwa, starości lub w czasie poważnej choroby. Tego typu relacje zależności szczególnie ekonomiczno-produkcyjnej współtworzą całe konkretne społeczeństwa.

Uwzględnienie perspektywy troski w myśleniu o relacjach społecznych nadaje im nową jakość. Diana T. Meyers uważa wręcz za rewolucyjne przedstawione przez Held myślenie o społeczeństwie i jego zasadach. Propozycja odwołania się do relacji między matczyną osobą a dzieckiem w perspektywie społecznej przeciwstawia się silnie myśleniu zakorzenionemu we współczesnych zachodnich społeczeństwach na temat relacji społecznych, które powstają w wyniku kontraktu. Od XVII wieku pogląd ten był silnie związany z rozpatrywaniem sprawiedliwości jako przestrzeni dla uczciwej transakcji (fair deal), w ramach której powstaje porozumienie przez dobrowolne uczestnictwo równych stron. Meyers wytyka współczesnym filozofom, że skuteczność idei społecznego kontraktu nie jest poddawana dyskusji i zapomina się, iż jest ona metaforą sprawiedliwości i relacji ${ }^{43}$.

W ramach etyki troski proponowanej przez Held odrzucone zostaje liberalne indywidualistyczne rozumienie człowieka. Liberalne ,ja” jest ujmowane w dwóch zasadniczych kontekstach. Po pierwsze, przedstawiciele wspomnianych teorii rozpatrują człowieka jako egoistyczne indywiduum. Po drugie, traktują człowieka jako „uniwersum” obdarte z cech jednostkowych, którym może być każdy, lub traktują ludzi jako innych, rozumianych ogólnie. Jej zdaniem, co wydaje się słuszne, tradycyjne etyki zgadzają się na tę dwubiegunowość ,ja”, czyli z jednej strony na jego indywidualność, z drugiej zaś na bycie uniwersalnym przedstawicielem wszystkich ludzi ${ }^{44}$. W opo-

\footnotetext{
${ }^{43}$ MeYers, „Tropes of Social Relations”: 49.

${ }^{44}$ HeLd, Feminist Morality, 57.
} 
zycji do takiego myślenia, z perspektywy troski, człowieka traktuje się jako osobę relacyjną, która ma realne predyspozycje, doświadczenia, a przede wszystkim jest współzależna od innych ${ }^{45}$.

W teoriach liberalnych ${ }^{46}$ rażący jest dla Held brak koncepcji osoby jako obywatela. Proponowane przez liberalizm stanowisko przedstawia indywidualnego uczestnika życia społecznego, który jest wyabstrahowany z więzi społecznych i umieszczany $w$ idealnych okolicznościach dorosłej osoby. Taka koncepcja pomija społeczne relacje ekonomii, które tworzą w obrębie wspólnoty bardzo współzależni od siebie jej członkowie. Osoby jako podmioty każdej narodowej ekonomii są głęboko zależne od siebie i ciągle wzrasta ich zależność od innych, i to na całym świecie. W liberalnej teorii polityki nie zwraca się uwagi także na czas dzieciństwa oraz wzrastający odsetek osób starszych, które stanowią olbrzymi odsetek społecznej populacji ${ }^{47}$. Nie można większości czasu przeżywanego przez ludzi i związanych z nim potrzeb sprowadzić do usług, które autonomiczne, egoistyczne indywidua mogą zakupić na wolnym rynku lub sobie zabezpieczyć. Held sugeruje, że ludzie potrzebują i chcą relacji troski, która wymyka się modelowi człowieka jako ogółu wolnych i równych indywiduów, wyrażających zgodę na kontrakt określony społecznie ${ }^{48}$.

Na poziomie globalnego społeczeństwa i konkretnych wspólnot politycznych powinny być, na co wskazuje Held, rozwijane struktury troski (caring about and for) „każdy o każdego” jako istniejących ludzi, którzy są członkami rodzin i grup. Powinno się troszczyć o każdego jako osobę będącą w potrzebie. Dopiero wewnątrz rozpoznawanej struktury troski osoby moga być widziane jako mające uprawnienia i jako zasługujące na zapewnienie większej sprawiedliwości. Natomiast tylko w takich dziedzinach jak prawo, Held jest w stanie przyznać pierwszeństwo sprawiedliwości ${ }^{49}$. Dodaje jednak, że

\footnotetext{
${ }^{45}$ Virginia Held, „Feminist Transformations of Moral Theory,” Philosophy and Phenomenological Research 50 (1990), No. Supplement Autumn: 337-44.

${ }^{46}$ Held w swoich krytykach teorii liberalnych najczęściej odnosi się do przedstawicieli: teorii sprawiedliwości (J. Rawlsa, B. Barry’ego), umowy społecznej (D. Gauthiera), a także liberalnych feministek (M. Nussbaum, S.M. Okin). Nie przeprowadza jednak szczegółowych analiz wybranych pojedynczych zagadnień. Dlatego nie można dokonać w sposób bardziej szczegółowy przeglądu jej argumentacji wystosowanej do konkretnych liberalnych i indywidualistycznych koncepcji.

${ }^{47}$ Held, The Ethics of Care, 81.

${ }^{48}$ Ibid.

${ }^{49}$ Virginia Held, „Care and Justice, Still”, w: Care Ethics and Political Theory, red. Daniel Engster i Maurice Hammington (Oxford: Oxford University Press, 2015), 19-36; EADEM, The Ethics of Care, 72.
} 
potrzebne jest nam rozpoznanie wartości wypływającej z praktyki troski w celu zrozumienia istoty troskliwego postępowania ludzkiego. Dlatego w odpowiedzi na pytanie postawione na początku artykułu, jaka jest relacja między troską a sprawiedliwością, należy powiedzieć, że troska może istnieć bez sprawiedliwości, ale sprawiedliwość nie może istnieć bez troski, rozpoznawanej jako wartość ${ }^{50}$.

\section{UMOWA SPOŁECZNA I WSPÓLNOTA OBYWATELSKA}

Jeżeli istotę podmiotu moralnego ma stanowić jego relacyjność, to relacje współtworzą również jego tożsamość. Sieć relacji, w które osoba jest zaangażowana, odciska się nie tylko w jej świadomości, ale i społecznym postrzeganiu lub obrazie tej osoby. Jeżeli relacje są także czymś, co człowiek spotyka od chwili narodzin, a nawet wcześniej, to są one dostrzegane bardziej jako pewna konieczność związana z ludzką egzystencją niż coś, co swobodnie może być tworzone, zrywane lub formowane. Dlatego społeczeństwo jest postrzegane przez Held organicznie, a nie atomistycznie. Istniejące relacje nie są rozpatrywane jako dobrowolne, ale jako konieczne i stanowiące podstawę społeczeństwa. Wizja społeczeństwa zaproponowana przez Held przeciwstawia się wizji społeczeństwa przedstawianych przez teorie kontraktualne. W prowadzonych dyskursach ustosunkowuje się ona przede wszystkim do wizji społeczeństwa konstruowanej na podstawie koncepcji umowy społecznej. Held wskazuje, podobnie jak Annette C. Baier ${ }^{51}$, wręcz na fanatyczne zaufanie, jakim kultura zachodnia obdarowała relacje między uczestnikami kontraktu wyrażonego w formie umowy społecznej. Dlatego podejmuje ona starania zmierzające do zmiany lub co najmniej modyfikacji takiej wizji zaufania ${ }^{52}$. Jej poglądy bardzo trafnie przedstawia Seyla Benhabib. Analizując Hobbesowski stan natury, pisze: „Dziwny jest świat, w którym jednostki pojawiają się niczym grzyby, to znaczy stają się dorosłe, nim się narodziły, w którym chłopcy są mężczyznami, nim byli dziećmi, w którym są jacyś inni, ale nie ma ani sióstr, ani matek, ani żon"53.

\footnotetext{
${ }^{50}$ EADEM, The Ethics of Care, 134.

${ }^{51}$ Anette C. BAIER, „Trust and Antitrust”, w: Feminist Social Thought. A Reader, red. Diana T. Meyers (New York, London: Routledge, 1997): 607.

${ }^{52}$ HeLd, The Ethics of Care, 131-132.

${ }^{53}$ Seyla BenhabiB, Situating the Self: Gender, Community and Postmodernism in Contemporary Ethics (New York: Routledge, 1992), 157 - cyt. za: Magdalena ŚRODA, Indywidualizm
} 
Przedstawiciel liberalizmu, jakim jest John Rawls, zwraca uwage na to, że nierówność w bogactwie musi zakładać, iż każdy $\mathrm{z}$ obywateli posiada minimum dóbr niezbędnych do przetrwania. Możemy więc stwierdzić, że stosuje on pewien redukcjonizm, sądząc, że dobrobyt i bogactwo są w stanie zaspokoić minimum do przetrwania społeczeństwa. $Z$ jednej strony Held uważa, że Rawlsowi umyka fakt, iż dziecku zaraz po urodzeniu nie wystarczy zapewnić pokarm, dostarczając go w sposób mechaniczny. Niezbędne jest również wieloletnie otoczenie troską kochającej osoby, aby dziecko mogło przeżyć i w pełni się rozwijać. Z drugiej strony nie dostrzega, że Rawls tego nie wyklucza. Niemniej w ten sposób uwidacznia się różnica między Rawlsem a Held w patrzeniu na potrzeby. Autor Teorii sprawiedliwości rozpatruje potrzeby wyłącznie jako materialne, natomiast dla Held potrzeby mają także wymiar niematerialny, np. potrzeba czucia czyjejś bliskości, bycia ważnym dla kogoś, potrzeba osobistego rozwoju.

Model kontraktowych relacji, które stanowią w większości teorii liberalnych wzór wszelkich relacji, jest modelem ograniczonych relacji odpowiednich dla różnych regionów ludzkiej aktywności. Według Carole Pateman i Virginii Held relacja wymiany między kupującym a sprzedającym jest często traktowana jako model wszystkich ludzkich wzajemnych odniesień ${ }^{54}$. Przedstawiciele tradycji umowy społecznej postrzegają tę relację jako fundamentalną dla prawa i politycznego autorytetu oraz ekonomicznej działalności. Stąd wielu współczesnych filozofów moralności, takich jak David Gauthier, wierzy, że nawet moralność sama w sobie powinna być oparta na relacjach kontraktowych ${ }^{55}$.

Held roztacza wizję społeczeństwa, w którym dyskusje o wspólnocie i społeczeństwie obywatelskim koncentrują się na takich zbiorowościach, które nie są ani rodzinnymi, ani neutralnymi, ani bezosobowym liberalnym rządem utworzonym do wyłonienia zasad sprawiedliwości. Członkowie społeczeństwa obywatelskiego rozwijają, jej zdaniem, wystarczające uczucia empatii dla drugich poprzez zaangażowanie się w zwykłe projekty, np. ratowania historycznych budynków, sprzątania parków. W tego typu wspólnocie rozwój cnót obywatelskich, takich jak gotowość do wysłuchania innych i do zaangażowania się w dyskusję, dokonuje się z pełnym szacunkiem dla ich potrzeb i interesów. W takich wspólnotach priorytetem nie jest rezultat oparty

i jego krytycy. Wspótczesne spory między liberałami, komunitarianami i feministkami na temat podmiotu, wspólnoty i ptci (Warszawa: Fundacja Aletheia, 2003).

${ }^{54}$ Carole Pateman, The Sexual Contract (Cambridge: Stanford University Press, 1988), 20-22.

${ }^{55}$ David Gauthier, Morals by Agreement (Oxford: Oxford University Press, 1986). 
na utylitarystycznej kalkulacji, uzyskany przez odseparowane od siebie jednostki. Nie jest nim również dokładne podążanie, w mniemaniu Held, za deontologicznymi regułami ściśle związanymi z prawnym kontekstem ${ }^{56}$.

Członkowie obywatelskich stowarzyszeń często dostrzegają, jak mocno są z sobą powiązani i jak bardzo podtrzymywanie więzi wśród członków stowarzyszenia wpływa na ich indywidualne korzyści. Widzą również, że zyski lub straty uzyskiwane przez członków danej grupy wpływają też na ich pomyślność. Wspólnoty obywatelskie są czymś więcej niż tylko instrumentami dla uzyskania satysfakcji z indywidualnych preferencji. Stowarzyszenia obywatelskie przekazują, zdaniem Held, prawdę o państwie, ukazując ich rozwój poprzez popieranie społecznego zaufania i sentymentów solidarności, czyli czynników, które sa prawie niewidoczne w liberalnym, racjonalnym i kontraktualnym wyborze ${ }^{57}$.

Held, podobnie jak Gilligan i Noddongs, uważa, że zajmując się etyką, można wyróżnić dwie główne perspektywy interpretacji problemów moralnych. Pierwsza — to perspektywa sprawiedliwości, druga — to perspektywa troski. W perspektywie sprawiedliwości podmioty moralne odwołują się do uniwersalnych moralnych zasad i sumienia. W perspektywie troski zwraca się większą uwagę na potrzeby ludzi i relacje między rzeczywistymi osobami ${ }^{58}$. Tworzy to istnienie odmiennych moralnie podejść dla różnych dziedzin. Zdaniem Held zwolennicy umowy społecznej niewłaściwie pojmują sprawiedliwość jako bezstronność, urzeczywistnianą w ramach relacji rodzinnych, ale także $\mathrm{w}$ relacjach społecznych ${ }^{59}$. Natomiast $\mathrm{w}$ relacjach społecznych kontraktualiści zapominają o wysokiej współzależności, jaka istnieje między obywatelami, również w wymiarze ekonomicznym. Nie należy jednak pomijać rozważań na temat sprawiedliwości w obu tych obszarach, chociaż zagadnienie sprawiedliwości nie powinno zajmować tyle miejsca w dyskursie moralnym i społecznym, ile zajmuje do tej pory. W odróżnieniu od Gilligan i Noddings, które utrzymują sztywny podział na troskę i sprawiedliwość, Held stara się je połączyć. Pyta, jak zintegrować obie wartości, czyli sprawiedliwość i troskę ${ }^{60}$.

Feministyczne rozumienie sprawiedliwości i troski umożliwia dostrzeżenie różnicy między obiema wartościami i ich różnych sposobów interpretacji

\footnotetext{
${ }^{56}$ Held, The Ethics of Care, 131.

${ }^{57}$ Held, The Ethics of Care, 131-132.

${ }^{58}$ EAdeM, Feminist Morality, 66.

${ }^{59}$ EADEM, The Ethics of Care, 69.

${ }^{60}$ Ibid., 65 .
} 
moralnych problemów. Feministyczna dyskusja rozpoczęta w latach dziewięćdziesiątych, dotycząca relacji między troską a sprawiedliwością, pokazała, że obie wartości potrzebują siebie nawzajem. Obie są bardzo ważne dla moralności ${ }^{61}$. Chociaż sprawiedliwość jest, zdaniem Held, z pewnością najważniejszą spośród moralnych wartości, to można bez niej kontynuować życie. Jako przykład takiej wspólnoty wskazuje rodzinę. W niej rozwijana jest sprawiedliwość, ale o wiele częściej i więcej spotykamy się z troską. Jest to dla Held wystarczający argument za tym, że możemy mieć troskę bez sprawiedliwości. Natomiast bez troski nie mogłoby być publicznego systemu uprawnień, nawet jeżeli byłyby one sprawiedliwe. Dlatego sprawiedliwość nie powinna spychać troski na margines, jak ma to miejsce m.in. u Rawlsa ${ }^{62}$.

\section{ZAKOŃCZENIE}

Etyka troski proponowana przez Virginię Held opiera się na relacyjnej koncepcji osoby, czyli takiej, która utrzymuje liczne relacje z innymi osobami. Relacje współzależności od innych są rozpoznawane jako istotna część stanowiąca o tożsamości osób i społeczeństw ${ }^{63}$. Sara Ruddick podkreśla, że Held już w dziele Feminist Morality rozpoczęła konstruowanie wizji społecznych więzi, w których rozpoznaje się wartość relacji troski i nie popada w altruizm. Ciężka praca, polegająca na troskliwej relacji z innymi, stanowi dla Held źródło moralnego spojrzenia ma stosunki międzyludzkie. Dlatego trudno jest wychwalać troskę bez jej idealizowania ${ }^{64}$.

Warto zwrócić również uwagę na problem troskliwych relacji między instytucjami państwowymi. Held, idealizując instytucje państwowe, wyobraża je sobie jako obywatelskie stowarzyszenia (pozarządowe), co wydaje się bardzo ciekawe, ale nie do końca uzasadnione. Główną trudność stanowi to, jak organizacje mogą być w cokolwiek zaangażowane emocjonalnie. Wydaje się, że relację troski między takimi instytucjami należy rozpatrywać raczej jako zbiór relacji między poszczególnymi członkami obu instytucji, a nie instytucjami jako pewnymi abstraktami. Held pomija również istotę funkcjo-

\footnotetext{
${ }^{61}$ Ibid., 68.

${ }^{62}$ HeLD, The Ethics of Care, 71-72.

${ }^{63}$ Ibid., 135.

${ }^{64}$ Sara RuDDICK, „Care as Labor and Relationship,” w: Norms and Values: Essays on the Work of Virginia Held, red. Joram Graf Haber and Mark S. Halfon (Lanham, Boulder, New York, Oxfrod: Rowman \& Littlefield Publishers, 1998), 4.
} 
nowania organizacji pozarządowych, jaką jest działanie dla wspólnie obranego celu. Trudna wyobrazić sobie troskliwą relację np. między stowarzyszeniem pro-choice a organizacją o charakterze pro life.

Kontrakt społeczny i myślenie o relacjach społecznych w kategoriach sprawiedliwości w wersji zaproponowanej przez Johna Rawlsa poddane zostały przez Held ostrej krytyce. Zapomina ona jednak o przeznaczeniu Rawlsowskiej teorii. Jest ona przewidziana jako narzędzie do ustalania zasad życia społecznego. Bezstronność planują inni, ale to nie oznacza, że nie można kierować się odruchami serca czy w sposób szczególny dbać o interesy najbliższych. Dla Rawlsa sprawiedliwość jako bezstronność stanowi pewne minimum dla społecznych relacji i nie wymaga on bezstronności w relacjach rodzinnych. Wręcz przeciwnie, jest świadomy występujących w nich stronniczości. Proponowana przez Rawlsa sprawiedliwość ma być gwarantem pluralizmu społecznego, o czym Held wydaje się zapominać.

Czy etyka troski proponowana przez Held jest tylko marzeniem, jak sugeruje Maciej Uliński? ${ }^{65}$ Wydaje się, że jest to krytyka przesadna. Nie zapominajmy, że jej projekt etyczny jest normatywny i wskazuje ideał relacji osobistych, społecznych i globalnych, a nie opis zastanej lub urojonej rzeczywistości. Held udziela wskazówek dotyczących rozwoju prawidłowych relacji troski w wymiarze społecznym. Najbardziej doniosłym jej wkładem w debatę o kondycji współczesnych społeczeństw jest jednak nadanie troskliwym relacjom międzyludzkim charakteru priorytetowego. Przyczyniła się do sprowadzenia debaty o obywatelach z liberalnych wizji, którzy ujmowani są w kategoriach abstrakcyjnych innych (pochodzących wręcz ze świata Platońskich idei), na grunt realnych obywateli posiadających swoje rzeczywiste relacje i historie życiowe. Właśnie $\mathrm{w}$ ramach tak postrzeganego człowiekaobywatela i społeczeństwa można dopiero rozwijać ideę troskliwych relacji.

Grunt przygotowany przez feministyczną etykę troski w jej klasycznym ujęciu, reprezentowana m.in. przez Virginię Held, w którym troskę postrzega się jako relację, jest w dalszym ciagu zagospodarowywany i rozwijany. Ma on nie tylko swoje kontynuatorki, takie jak np. Sarah Clark Miller, ale jest również rozwijany $w$ formie etyki cnót za sprawą Michaela Slote'a. Także teoria społeczeństwa minimalnie opiekuńczego, rozwijana przez Daniela Engstera, w bezpośredni sposób jest kontynuacją pomysłów Held na wizję relacji społecznych. Oznacza to, że kategoria troski na dobre zadomowiła się nie tylko w etyce, ale także znajduje sobie miejsce w teorii polityki.

\footnotetext{
${ }^{65}$ ULIŃSKI, Etyka troski i jej pogranicza, 103.
} 


\section{REFERENCJE}

BAIER, Annette C. Moral Prejudices: Essays on Ethics. Cambridge: Harvard University Press, 1994.

BAIER, Annette C. „Trust and Antitrust”. W: Feminist Social Thought. A Reader, red. Diana T. Meyers, 604-29. New York, London: Routledge, 1997.

BenHabiB, Seyla. Situating the Self: Gender, Community and Postmodernism in Contemporary Ethics. New York: Routledge, 1992.

BuBECK, Diemut. Care, Gender and Justice. Oxford: Oxford University Press, 1995.

CARothers, Suzanne. „Catching Sense: Learning from Our Mothers to Be Black and Female.” In Uncertain Terms, red. Faye Ginsburg i Anna Tsing. Boston: Beacon Press, 1990.

Flanagan, Owen, i Kathryn JACKSON. „Justice, Care, and Gender: The Kohlberg-Gilligan Debate Revisited.” Ethics 97 (1987), No. 3 (April): 622-637. DOI: https://doi.org/10.1086/292870.

FouCAult, Michel. Historia seksualności. Warszawa: Czytelnik, 2000.

Friedman, Marilyn. What Are Friends For?: Feminist Perspectives on Personal Relationships and Moral Theory. Ithaca: Cornell University Press, 1993.

Gauthier, David. Morals by Agreement. Oxford: Oxford University Press, 1986.

Gilligan, Carol. In a Different Voice: Psychological Theory and Women's Development. Cambridge: Harvard University Press, 1982.

Grimshaw, Jean. „Czy istnieje etyka kobieca?” W: Przewodnik po etyce, red. Peter Singer. Przełożyli Robert Pucek, Paweł Łuków i in. Warszawa: Wydawnictwo KsIĄżKA I WIEDZA, 2009.

Hadot, Pierre. Czym Jest filozofia starożytna? Przełożył Piotr Domański. Warszawa: Fundacja Aletheia, 2000.

Heidegger, Martin. Bycie i czas. Przełożył Bogdan Baran. Warszawa: Wydawnictwo Naukowe PWN, 1994.

Hekman, Susan J. Moral Voices, Moral Selves: Carol Giligan and Feminist Moral Theory. Pennsylvania: Pennsylvania State University Press, 1995.

Held, Virginia. „Care and Justice, Still”. W: Care Ethics and Political Theory, red. Daniel Engster i Maurice Hammington, 19-36. Oxford: Oxford University Press, 2015.

Held, Virginia. Feminist Morality: Transforming Culture, Society, and Politics. Chicago, London: The University of Chicago Press, 1993.

HeLd, Virginia. „Feminist Transformations of Moral Theory.” Philosophy and Phenomenological Research 50 (1990), No. Supplement Autumn: 321-344. DOI: https://doi.org/10.2307/2108046.

Held, Virginia. „Moral Subjects: The Natural and the Normative”. Proceedings and Addresses of the American Philosophical Association 76 (2002), No. 2 (November): 7-24. DOI: https://doi.org/ $10.2307 / 3218626$.

Held, Virginia. Rights and Goods. Justifying Social Action. Chicago: University of Chicago Press, 1989.

Held, Virginia. The Ethics of Care: Personal, Political, and Global. New York: Oxford University Press, 2006.

IRIGARAY, Luce. I Love to You: Sketch for a Felicity within History. New York-London: Routledge, 1996.

IrIGARAY, Luce. Sexes and Genealogies. New York: Columbia University Press, 1993.

KAMIŃSKA, Aleksandra. „,Spór wokół feministycznej etyki troski”. Praca doktorska, Uniwersytet Śląski w Katowicach, 2008 - dostępna on-line: https://sbc.org.pl/Content/12050/doktorat2884.pdf.

KOHLBERG, Lawrence. „From is to ought: How to commit the naturalistic fallacy and get away with it in the study of moral development", in Cognitive development and epistemology, red. Theodore Mischel, 151-235. New York: Academic Press, 1971.

KymlickA, Will. Współczesna filozofia polityczna. Przełożył Andrzej Pawelec. Kraków: Wydawnictwo Znak, 1998. 
MANNING, Rita. Speaking from the Heart: A Feminist Perspective on Ethics. Lanham: Rowman \& Littlefield Publishers, 1992.

MAYeroff, Milton. On Caring. New York: Harper \& Row, 1971.

MEYERS, Diana T. „Tropes of Social Relations and the Problem of Tropisms in Figurative Discourse”. W: Norms and Values: Essays on the Work of Virginia Held, red. Joram Graf Haber i Mark S. Halfon, 49-60. Lanham, Boulder, New York, Oxfrod: Rowman \& Littlefield Publishers, 1998.

Miller, Sarah Clark. The Ethics of Need. Agency, Dignity, and Obligation. New York: Routledge, 2012.

NodDINGS, Nel. Caring: A Feminine Approach to Ethics and Moral Education. Berkeley: University of California Press, 1984.

NodDings, Nel. The Maternal Factor: Two Paths to Morality. Berkeley: University of California Press, 2010.

OKIN, Susan Moller. „Reason and Feeling in Thinking about Justice”. Ethics 99 (1989), No. 2 (Jan.): 229-249. DOI: https://doi.org/10.1086/293064.

Pateman, Carole. The Sexual Contract. Cambridge: Stanford University Press, 1988.

REICHT, Warren T. "History of the Notion of Care". W: Encyclopedia of Bioethics, red. Warren T. Reicht. $2^{\text {nd }}$ ed., 319-331. New York: Macmillan Library Reference, 1995.

RUDDICK, Sara. „Care as Labor and Relationship”. W: Norms and Values: Essays on the Work of Virginia Held. Red. Joram Graf Haber i Mark S. Halfon, 3-25. Lanham, Boulder, New York, Oxford: Rowman \& Littlefield Publishers, 1998.

RuDDICK, Sara. "Maternal Thinking.” In Feminist Social Thought. A Reader. Red. Diana T. Meyers, 584-603. New York, London: Routledge, 1997.

SLote, M. Morals from Motives. New York: Oxford University Press, 2001.

SONIEwICKA, Marta. Granice Sprawiedliwości, Sprawiedliwość Ponad Granicami. Warszawa: Wolters Kluwer Polska, 2010.

ŚRODA, Magdalena. Indywidualizm i jego krytycy. Współczesne spory między liberałami, komunitarianami i feministkami na temat podmiotu, wspólnoty i ptci. Warszawa: Fundacja Aletheia, 2003.

StACK, Carol. „Different Voices, Different Visions: Gender, Culture, and Moral Reasoning.” W: Uncertain Terms. Red. Faye D. Ginsburg i Anna L. Tsing. Boston: Beacon Press, 1990.

Tronto, Joan C. „Beyond Gender Difference to a Theory of Care.” Signs: Journal of Women in Culture and Society 12 (1987), no. 4 (July): 644-63. DOI: https://doi.org/10.1086/494360.

Tronto, Joan C. Moral Boundaries. A Political Argument for an Ethic of Care. New York, London: Routledge, 1993.

UlińsKi, Maciej. Etyka Troski i Jej Pogranicza. Kraków: Wydawnictwo Aureus, 2012.

WALESZCZYŃSKI, Andrzej. Feministyczna etyka troski. Założenia i aspiracje. Warszawa: Środkowoeuropejski Instytut Zmiany Społecznej, 2013.

WALESZCZYŃSKI, Andrzej. „Pojęcie Troski We Współczesnej Etyce.” Studia Philosophiae Christianae 48, no. 2 (2012): 143-57.

WALSH, Joseph P. "Caring: A Pluralist Account." Ratio 31, no. S1 (2018): 96-110. DOI: https://doi.org/10.1111/rati.12179.

ZIEMIŃSKA, Renata. „Etyka troski i etyka sprawiedliwości. Czy moralność zależy od płci?” Analiza i Egzystencja 8 (2008): 115-32. 


\title{
MIĘDZY TROSKĄ A SPRAWIEDLIWOŚCIĄ. VIRGINII HELD POGLĄDY NA WSPÓLNOTĘ POLITYCZNĄ
}

\author{
Streszczenie
}

W artykule podjęta została analiza tego, co nowego do debaty o kondycji współczesnej wspólnoty politycznej wniosła dyskusja o relacji między troską a sprawiedliwością. Autor przybliża kategorię troski w filozofii i jej rozumienie ze szczególnym uwzględnieniem poglądów Virginii Held. Analizuje znaczenie relacji troski jako fundamentu dla prawidłowego funkcjonowania wspólnoty społecznopolitycznej i krytyki idei kontraktu społecznego podejmowane przez przedstawicielki etyki troski. W sposób krytyczny przedstawia konsekwencje założeń wspólnoty obywatelskiej przyjmowanych przez Held.

\section{BETWEEN CARE AND JUSTICE: \\ VIRGINIA HELD'S VIEWS ON THE POLITICAL COMMUNITY}

\section{Su m m a ry}

In this article, an analysis was made of what's new in the debate on the condition of the contemporary political community brought up by the discussion about the relationship between care and justice. The author introduces the category of care in philosophy and its understanding and with particular emphasis on the views of Virginia Held. He analyzes the importance of a relationship of care as the foundation for the proper functioning of the socio-political community and criticism of the idea of a social contract undertaken by representatives of the ethics of care. Critically, he presents the consequences of the assumptions of the civic community accepted by Held.

Słowa kluczowe; troska; sprawiedliwość; wspólnota polityczna; Virginia Held; etyka troski; liberalizm.

Key words; care; justice; political community; Virginia Held; ethics of care; liberalism.

Information about Author: ANDRZEJ WALESZCZYŃSKI, PhD - the Cardinal Stefan Wyszynski University, Faculty of Christian Philosophy, Institute of Philosophy; address for correspondence: ul. Wóycickiego 1/3. 01-938 Warszawa; e-mail: a.waleszczynski@uksw.edu.pl; ORCID: http://orcid.org/0000-0003-0426-3919. 